\title{
ANALISIS PROSES, BIAYA PENGEMBANGAN, DAN ADDED VALUESISTEM INFORMASI AKUNTANSI PELAYANAN RAWAT JALAN DAN RAWAT INAP PADA RUMAH BERSALIN DAN KLINIK GEBANG MEDIKA
}

\author{
Oleh: \\ Hapsari Widayani \\ Program Studi Pendidikan Ekonomi \\ Fakultas Ilmu Pendidikan dan Pengetahuan Sosial \\ Universitas Indraprasta PGRI \\ Email: \\ hwidayani@gmail.com
}

\begin{abstract}
ABSTRAK
Tujuan penelitian ini adalah untuk menganalisis proses dan prosedur sistem informasi akuntansi pelayanan rawat jalan dan rawat inap Rumah Bersalin dan Klinik Gebang Medika dan menganalisis biaya pengembangan dan cara menciptakan added value Rumah Bersalin dan Klinik Gebang Medika. Metode pengumpulan data dilakukan dengan pengamatan langsung ke objek penelitian yaitu Rumah Bersalin dan Klinik Gebang Medika dan data yang digunakan adalah data primer. Hasil penelitian ini menjelaskan bahwa terdapat perbedaan jumlah biaya pengembangan antara sistem lama dan sistem baru. Sistem lama membutuhkan biaya pengembangan proyek selama setahun sebesar Rp 82.195.200,- sedangkan sistem baru membutuhkan biaya pengembangan proyek sebesar Rp 83.755.350,-. Selisih ini akibat adanya sejumlah biaya yang harus dikeluarkan yakni biaya analisis dan desain, biaya installasi, biaya implementasi, dan biaya lain-lain yang besar nilainya. Penambahan nilai (value-added) pada klinik ini, yaitu (1) mengoptimalkan kualitas pelayanan yang bersumber dari akurasi hasil pemeriksaan dan kemudahan akses pelayanan pasien, (2) meningkatkan efisiensi waktu pelayanan dan pembuatan laporan saat pasien mendaftar, (3) meningkatkan struktur pengendalian internal terbaru yang dapat diakses setiap otorisasi yang bertanggung jawab, (4) meningkatkan pengambilan keputusan ialah manajemen klinik dapat menggunakan informasi yang akurat yang dihasilkan oleh sistem baru untuk pengambilan keputusan jangka panjang.

Kata kunci: Sistem Informasi Akuntansi, Pasien Rawat Jalan, Pasien Rawat Inap, Analisis Pengembangan Proyek, Value-added
\end{abstract}




\section{A. PENDAHULUAN}

Dewasa ini kesehatan merupakan salah satu kebutuhan utama masyarakat di Indonesia. Dengan memiliki kesehatan dan kondisi fisik yang baik tentunya akan memudahkan dalam mencari penghasilan, mendapatkan pendidikan yang layak, juga dapat meningkatkan taraf hidup masing-masing individu. Dalam UndangUndang Nomor 29 Tahun 2004 tentang Praktek Kedokteran dijelaskan bahwa kesehatan sebagai hak asasi manusia harus diwujudkan dalam bentuk pemberian upaya kesehatan kepada seluruh masyarakat melalui penyelenggaraan pelayanan kesehatan yang berkualitas dan terjangkau oleh masyarakat.

Salah satu sarana kesehatan yang berkualitas dan terjangkau oleh masyarakat adalah klinik. Menurut Peraturan Menteri Kesehatan Nomor 028/MENKES/PER/I/2011 pasal 1, klinik adalah fasilitas pelayanan kesehatan yang menyelenggarakan pelayanan kesehatan perorangan yang menyediakan pelayanan medis dasar dan/atau spesialistik, diselenggarakan oleh lebih dari satu jenis tenaga kesehatan dan dipimpin oleh seorang tenaga medis.

Pertumbuhan klinik di Indonesia sudah sangat tinggi terlihat dari menjamurnya klinik di berbagai daerah di Indonesia. Peningkatan jumlah klinik ini tentunya harus disertai dengan peningkatan pelayanan sehingga klinik yang ada semakin prima dalam melayani masyarakat Salah satu hal yang dilakukan adalah bekerja sama dengan BPJS dan menggunakan sistem yang terintegrasi dengan baik.

Badan Penyelenggara Jaminan Sosial (BPJS) Kesehatan adalah badan hukum yang dibentuk untuk menyelenggarakan program jaminan kesehatan. BPJS Kesehatan ini sudah mulai beroperasi pada 1 Januari 2014 dan semua penduduk Indonesia wajib menjadi peserta BPJS termasuk orang asing yang telah bekerja paling singkat enam bulan di Indonesia dan telah membayar iuran (Kemenkes, 2013). Salah satu klinik yang sudah melakukan kerja_sama dengan BPJS Kesehatan adalah Rumah Bersalin dan Klinik Gebang Medika.Klinik tersebut telah melakukan kerja sama dengan BPJS Kesehatan mulai awal tahun 2014 dan setelah itu pengunjung (pasien) klinik ini mengalami peningkatan yang cukup signifikan. Data ini dapat dilihat pada Tabel 1.

Tabel 1.

Jumlah Pengunjung (Pasien) Klinik Gebang Medika Tahun 2013-2015

\begin{tabular}{clccc}
\hline No & Bulan & Tahun 2013 & Tahun 2014 & Tahun 2015 \\
\hline 1 & Januari & 1489 & 930 & 2276 \\
2 & Februari & 1429 & 974 & 2616 \\
3 & Maret & 1306 & 1143 & 2886 \\
4 & April & 1074 & 1282 & 2843 \\
5 & Mei & 1249 & 1133 & 2826 \\
6 & Juni & 1263 & 1200 & 2816 \\
7 & Juli & 1110 & 1024 & 2788 \\
8 & Agustus & 1058 & 1569 & 3482 \\
9 & September & 1233 & 1541 & 3501 \\
10 & Oktober & 1147 & 1626 & 3847 \\
11 & November & 1004 & 1848 & 3866 \\
\hline
\end{tabular}




\begin{tabular}{ccccc}
\hline 12 & Desember & 966 & 2037 & 3699 \\
TOTAL & $\mathbf{1 4 . 3 2 8}$ & $\mathbf{1 6 . 3 0 7}$ & $\mathbf{3 7 . 4 4 6}$ \\
\hline
\end{tabular}

Sumber: Arsip Klinik Gebang Medika, (2015)

Peningkatan jumlah pengunjung (pasien) klinik ini tidak dibarengi dengan kemajuan sistem yang digunakan. Sistem yang digunakan oleh Klinik Gebang Medika masih bersifat manual sehingga membutuhkan sebuah sistem informasi yang terintegrasi dengan baik dan memberikan informasi yang akurat. Sistem informasi merupakan cara untuk menghasilkan informasi yang berguna, cepat, akurat, dan tepat waktu. Informasi yang berguna akan mendukung sebuah pengambilan keputusan bagi pemakainya dan melakukan tindakan secara tepat berdasarkan informasi yang dihasilkan tersebut (S, Prasetijo, Budi, \& Handoyo, 2011).

Salah satu sistem informasi yang dibutuhkan adalah sistem informasi akuntansi pelayanan pasien rawat jalan dan rawat inap. Unit rawat inap dan rawat jalan ini merupakan unit yang setiap harinya melakukan aktivitas pelayanan terhadap pasien. Pasien yang diterima di klinik akan mendapatkan pelayanan pengobatan dan diberikan diagnosa oleh dokter selanjutnya dapat dirujuk, kontrol ulang, dirawat atau mendapat rujukan untuk dilakukan pemeriksaan penunjang medis diantaranya laboratorium, rontgen maupun rehabilitas medik.

Dengan adanya sistem informasi akuntansi terhadap pelayanan pasien di klinik ini diharapkan dapat memberikan pelayanan yang prima kepada masyarakat dan memaksimalkan kinerja semua pegawai klinik. Sistem informasi akuntansi juga dapat menambah nilai (value-added) terhadap sebuah organisasi termasuk pada klinik ini dengan cara mengoptimalkan kualitas pelayanan, meningkatkan efisiensi waktu pelayanan terhadap pasien, dan meningkatkan pengambilan keputusan. Sehingga dengan adanya sistem ini diharapkan informasi dan hasil pemeriksaan yang diberikan akurat, waktu pelayanan terhadap pasien lebih cepat, serta pengambilan keputusan jangka panjang dapat dilakukan secara lebih tepat dan terencana dengan baik.

Di sisi lain, peningkatan kinerja dan pelayanan kepada masyarakat seperti yang telah digambarkan di atas dan disertai dengan usulan penggunaan sistem yang lebih terkomputerisasi akan membuat masyarakat menjadi lebih percaya terhadap pelayanan klinik sehingga menjadi pelanggan tetap klinik ini. Hal ini akan membuat laba klinik menjadi lebih meningkat. Peningkatan laba klinik tentunya akan membuat klinik lebih mengabdikan diri terhadap masyarakat sekitar dengan memberikan kontribusinya seperti menyediakan sunat massal dan pengobatan secara gratis.

Berdasarkan uraian di atas, tujuan dari penelitian ini adalah menganalisis proses dan prosedur sistem informasi akuntansi pelayanan rawat jalan dan rawat inap Rumah Bersalin dan Klinik Gebang Medika. Selain itu, untuk menganalisis biaya pengembangan dan cara menciptakan added value terhadap sistem informasi akuntansi pelayanan pasien rawat jalan dan rawat inap Rumah Bersalin dan Klinik Gebang Medika. 


\section{B. KAJIAN PUSTAKA}

\section{Sistem Informasi Akuntansi}

Menurut (Romney \& Steinbart, 2014, p. 28), sistem informasi akuntansi adalah sistem yang mengumpulkan, mencatat, menyimpan, dan memproses data sehingga menghasilkan informasi untuk sebuah keputusan. Sistem informasi akuntansi adalah kumpulan sumber daya seperti orang dan perlengkapan, yang dirancang untuk mengubah data keuangan dan data lainnya menjadi informasi (Bodnar \& Hopwood, 2007)

\section{Rawat Jalan}

Menurut Keputusan Menteri Kesehatan RI Nomor 560/MENKES/SK/IV/2003 tentang tarif rumah sakit bahwa pasien rawat jalan adalah pelayanan pasien rawat jalan adalah pelayanan pasien untuk observasi, diagnosis, pengobatan rehabilitas, medis, dan pelayanan kesehatan lainnya tanpa menginap.

\section{Rawat Inap}

Rawat inap tingkat lanjutan menurut Menteri Kesehatan RI Nomor 138/MENKES//PB/II/2009 adalah pelayanan kesehatan perorangan yang bersifat spesialistik atau sub-spesialistik untuk keperluan observasi, perawatan, diagnosis, pengobatan, rehabilitasi medis dan/atau pelayanan medis lainnya termasuk konsultasi psikologi, yang dilaksanakan pada PPK (Pemberi Pelayanan Kesehatan) tingkat lanjutan di mana peserta atau anggota keluarganya dirawat inap di ruang perawatan paling singkat satu hari.

\section{Nilai Tambah (Value-Added)}

Menurut (Romney \& Steinbart, 2014, p. 11), sistem informasi akuntansi yang didesain dengan baik dapat menambah nilai (value-added) untuk sebuah organisasi yaitu dengan cara :

1. Meningkatkan kualitas dan mengurangi biaya produk atau jasa;

2. Meningkatkan efisiensi;

3. Berbagi pengetahuan;

4. Meningkatkan struktur pengendalian internal;

5. Meningkatkan pengambilan keputusan

Added value adalah aktivitas yang dalam prespektif konsumen memberikan nilai tambah pada produk atau jasa. Termasuk di dalamnya adalah memproses material menjadi produk setengah jadi atau produk jadi (Tebiary, Suastika, \& Ma'ruf, 2017).

\section{METODE PENELITIAN}

Data primer yang digunakan adalah data jumlah pengunjung (pasien), data jumlah pegawai, juga proses dan prosedur yang sudah diterapkan pada Rumah Bersalin dan Klinik Gebang Medika. Sedangkan data sekunder yang digunakan adalah struktur organisasi, kartu berobat, daftar hadir pasien umum dan BPJS, 
kartu rekam medis, salinan resep, surat kontrol pasien, surat keterangan sakit, kuitansi pembayaran, serta laporan keuangan.

Metode pengumpulan data dalam penelitian ini ialah observasi, wawancara, dan analisis data. Sedangkan metode pengembangan sistem melalui beberapa tahap, yaitu (1) tahap perencanaan sistem, (2) tahap analisis sistem, (3) tahap perancangan sistem, (4) tahap implementasi sistem, serta (5) tahap pengujian dan penggunaan sistem.

\section{HASIL DAN PEMBAHASAN}

\section{Data Flow Diagram}

\section{Diagram Context}

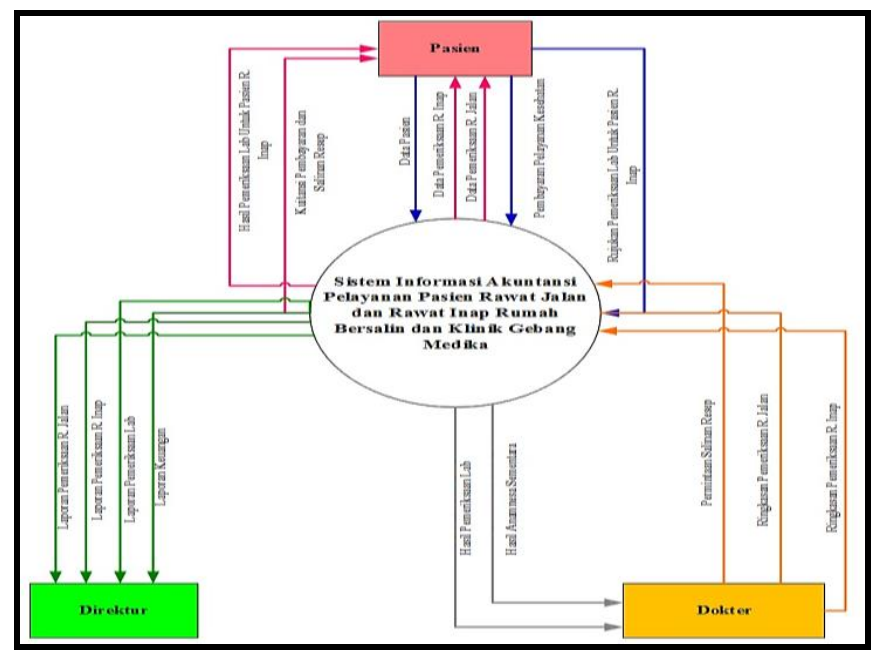

Gambar 1.

Diagram Context Sistem Informasi Akuntansi Pelayanan Pasien Rawat Jalan dan Rawat Inap Rumah Bersalin dan Klinik Gebang Medika Sumber : Data Diolah, (2016)

Diagram context merupakan level tertinggi dari Data Flow Diagram (DFD) yang menggambarkan seluruh input ke sistem atau output dari sistem. Dari diagram context di atas menunjukkan bahwa sistem informasi akuntansi pelayanan pasien rawat jalan dan rawat inap diawali dengan pasien yang mendaftarkan diri ke klinik dengan memberikan informasi tentang data diri secara detail kemudian data pasien tersebut diolah oleh sistem dan menghasilkan data pemeriksaan rawat jalan dan inap. Setelah proses pendaftaran selesai, pasien melakukan test tanda-tanda vital dan ditanya keluhan penyakitnya oleh perawat. Hasil anamnesis sementara diberikan oleh sistem ke dokter yang memeriksa. Setelah pemeriksaan selesai dan dokter masih belum dapat menetapkan diagnosis terhadap pasien maka pasien akan mendapat rujukan pemeriksaan laboratorium dan sistem akan mengeluarkan hasil laboratorium tersebut melalui bagian 
laboratorium. Laporan tersebut akan dilaporkan dan diperiksa oleh direktur tiap akhir bulan. Sistem juga akan mengeluarkan hasil laboratorium tersebut untuk dokter agar bisa mendiagnosis penyakit pasien serta dapat membuat dan melakukan input ringkasan pemeriksaan rawat jalan dan inap. Dokter juga melakukan input permintaan salinan resep ke sistem yang nantinya akan diberikan ke pasien setelah pasien melakukan pembayaran pelayanan kesehatan. Pasien akan mendapatkan kuitansi pembayaran dan salinan resep sebagai output-nya. Pada akhir bulan sistem akan mengeluarkan laporan rawat jalan dan inap yang dibuat oleh dokter dan laporan keuangan serta laporan tersebut diserahkan kepada direktur untuk diperiksa.

\section{Diagram Context}

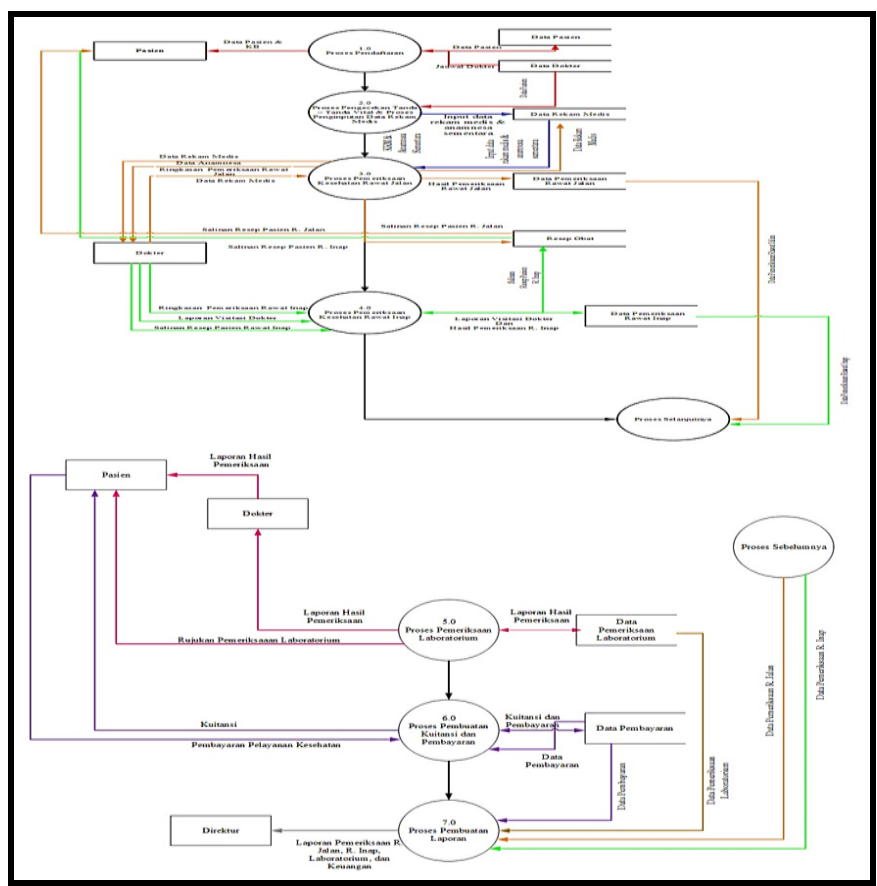

Gambar 2.

Diagram Zero Sistem Informasi Akuntansi Pelayanan Pasien Rawat Jalan dan Rawat Inap Rumah Bersalin dan Klinik Gebang Medika

Sumber: Data Diolah, (2016)

Diagram zero adalah diagram yang menggambarkan seluruh proses yang terjadi di diagram context. Pada sistem pelayanan rawat jalan dan inap pada Klinik Gebang Medika ini terdapat tujuh proses. Gambar diagram zero dapat dilihat pada Gambar 2.

Proses pertama adalah proses pendaftaran. Pada proses ini, pasien memberikan data pasien ke bagian pendaftaran. Bagian pendaftaran menginput data tersebut ke dalam sistem. Sistem akan mengeluarkan output berupa data pasien yang akan melakukan pemeriksaan pada klinik ini dan kartu berobat yang akan diserahkan kembali ke pasien. Setelah pasien melakukan pendaftaran, pasien akan mendapatkan jadwal dokter untuk mengetahui siapa sajakah dokter yang 
bertugas. Data input pasien ini akan disimpan pada database data pasien dan database data dokter akan mengeluarkan jadwal dokter.

Proses kedua adalah proses pengecekan tanda-tanda vital dan proses penginputan data rekam medis. Proses ini membutuhkan input data pasien yang diperoleh dari proses sebelumnya. Proses ini menghasilkan output yaitu input rekam medis dan anamnesis sementara. Proses anamnesis dilakukan perawat untuk mengetahui keluhan yang diderita pasien. Sementara input rekam medis dilakukan oleh bagian rekam medis. Penginputan rekam medis ini dilakukan agar dokter atau bidan yang memeriksa tahu akan riwayat pasien. Output ini disimpan pada database data rekam medis dan akan selalu update bila terjadi perubahan. Data rekam medis dan anamnesis sementara akan dibawa ke proses selanjutnya.

Proses ketiga adalah proses pemeriksaan kesehatan rawat jalan. Proses ini membutuhkan input yaitu data rekam medis dan anamnesis sementara yang diperoleh dari proses sebelumnya. Input ini di proses dan menghasilkan data rekam medis dan data anamnesis selanjutnya diberikan kepada dokter. Kemudian dokter melakukan pemeriksaan kepada pasien setelah itu membuat ringkasan pemeriksaan rawat jalan serta melakukan update data rekam medis. Proses terakhir yang dilakukan dokter adalah membuat salinan resep untuk pasien agar dapat digunakan untuk membeli obat di apotek terdekat. Ringkasan pemeriksaan rawat jalan, data rekam medis, dan salinan resep di-proses oleh sistem dan output nya di simpan pada database yang berbeda. Hasil pemeriksaan disimpan pada database pemeriksaan rawat jalan, data rekam medis disimpan pada database rekam medis, dan salinan resep disimpan pada database resep obat. Salinan resep pasien rawat jalan itu akan diberikan kepada pasien setelah selesai melakukan pembayaran.

Proses keempat adalah proses pemeriksaan kesehatan rawat inap. Proses ini membutuhkan input yaitu hasil pemeriksaan rawat jalan yang diperoleh dari proses ketiga. Input ini diproses pada sistem. Selanjutnya dokter melakukan pemeriksaan terhadap pasien dan membuat ringkasan pemeriksaan rawat inap. Dokter juga membuat laporan visitasi di mana visitasi itu dilakukan sebanyak satu kali dalam sehari. Terakhir dokter membuat salinan resep untuk pasien yang sudah diperbolehkan untuk pulang. Selain itu, dokter juga membuat surat rujukan pemeriksaan laboratorium dan diserahkan kepada pasien jika penyakit yang diderita pasien cukup serius dan membutuhkan hasil laboratorium untuk membantu melakukan diagnosis terhadap pasien. Surat rujukan itu kemudian diserahkan kepada petugas laboratorium. Output dari proses keempat adalah hasil pemeriksaan rawat inap, laporan visitasi dokter, dan salinan resep. Hasil pemeriksaan rawat inap dan laporan visitasi dokter disimpan pada database data pemeriksaan rawat inap. Sedangkan salinan resep disimpan pada database resep obat. Salinan resep itu juga diberikan kepada pasien rawat inap jika pasien telah selesai melakukan pembayaran.

Proses kelima adalah proses pemeriksaan laboratorium. Surat rujukan yang dibawa oleh pasien diserahkan kepada petugas laboratorium. Petugas laboratorium lalu melakukan pemeriksaan (cek) darah kepada pasien. Setelah hasil pemeriksaan keluar, kemudian diberikan kepada dokter agar dapat melakukan diagnosis terhadap pasien. Setelah itu dokter menyerahkan kembali ke pasien saat akan 
pulang. Petugas laboratorium kemudian membuat laporan hasil pemeriksaan dan datanya disimpan dalam database pemeriksaan laboratorium.

Proses keenam adalah proses pembuatan kuitansi dan pembayaran. Kasir membuat dua rangkap kuitansi pembayaran. Satu rangkap untuk pasien dan satu rangkap lainnya untuk disimpan pada database. Kuitansi rangkap satu_diserahkan kepada pasien dan pasien melakukan pembayaran. Uang dan kuitansi yang diterima oleh kasir kemudian diberikan kepada bagian keuangan. Sedangkan kuitansi disatukan oleh kasir dan di input ke dalam sistem dan menghasilkan data pembayaran. Jika telah selesai kuitansi dan data pembayaran disimpan pada database data pembayaran.

Proses ketujuh atau yang terakhir adalah proses pembuatan laporan. Proses ini dilakukan oleh bagian akuntansi. Proses ini membutuhkan input data pemeriksaan rawat jalan, data pemeriksaan rawat inap, pemeriksaan laboratorium dan data pembayaran. Semua data tersebut diolah sistem dan menghasilkan output berupa laporan rawat jalan, laporan rawat inap, pemeriksaan lab, dan laporan keuangan. Semua laporan itu diserahkan kepada direktur untuk diperiksa dan disetujui.

\section{Analisis Biaya Pengembangan Proyek Sistem Informasi Akuntansi Pelayanan Pasien Rawat Jalan dan Rawat Inap pada Rumah Bersalin dan Klinik Gebang Medika}

Biaya pengembangan proyek terdiri dari dua yaitu analisis sistem lama dan analisis sistem yang baru. Terdapat perbedaan jumlah biaya pengembangan proyek antara sistem lama dan sistem baru. Sistem lama membutuhkan biaya pengembangan proyek selama setahun sebesar Rp 82.195.200,- (tabel 2) sedangkan sistem baru membutuhkan biaya pengembangan proyek selama setengah tahun (enam bulan) sebesar Rp 41.877.675,- (tabel 3). Jika di amati, biaya pengembangan sistem baru terlihat lebih besar bila di kalkulasikan selama setahun yaitu menjadi Rp 83.755.350,-. Hal ini disebabkan karena pada tahun pertama pengembangan proyek sistem baru terdapat sejumlah biaya yang harus dikeluarkan yakni biaya analisis dan desain, biaya installasi, biaya implementasi, dan biaya lain-lain yang besar nilainya.

Biaya installasi pada sistem baru jumlahnya cukup signifikan karena pemasangan (installasi) sebuah aplikasi baru membutuhkan seorang programmer yang andal. Klinik ini juga membutuhkan perencanaan sangat matang untuk membuat sebuah desain sistem baru yang sesuai dengan kebutuhan klinik. Sehingga pada tahun pertama pengembangan proyek sistem baru mengeluarkan biaya sebesar Rp 1.995.000,- (Tabel 3) yang merupakan salah satu selisih biaya yang cukup signifikan daripada sistem lama. Dengan adanya selisih antara biaya sistem lama dengan biaya sistem baru diharapkan sistem yang baru (sudah terkomputerisasi) akan memberikan masukan (feedback) terutama pendapatan (income) yang baik bagi klinik ini. Penjelasan terkait biaya pengembangan sistem lama dan sistem baru terdapat pada tabel dibawah ini : 
Tabel 2.

Analisis Biaya Pengembangan Proyek Sistem Lama

\begin{tabular}{|c|c|c|c|c|c|}
\hline \multicolumn{6}{|c|}{\begin{tabular}{|c|} 
SISTEM LAMA KLINIK GEBANG MEDIKA \\
\end{tabular}} \\
\hline \multirow{2}{*}{\multicolumn{2}{|c|}{ No }} & \multirow{2}{*}{ Keterangan } & \multicolumn{3}{|c|}{ Tahun Ke - n } \\
\hline & & & $\mathbf{0}$ & 1 & 2 \\
\hline \multirow[t]{6}{*}{$\mathbf{A}$} & & Biaya Persiapaan Operasi (Start-Up Cost) & & & \\
\hline & 1 & Biaya Persiapan Personil & & & \\
\hline & & a. Biaya rapat pendirian klinik & $\mathrm{Rp} \quad 2,400,000$ & & \\
\hline & 2 & Biaya Manajemen dan Staff & & & \\
\hline & & a. Biaya transportasi pegawai $(5 \times \mathrm{Rp} 40.000)$ & \begin{tabular}{ll|}
$\mathrm{Rp}$ & $2,400,000$ \\
\end{tabular} & & \\
\hline & & Total Biaya & 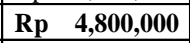 & & \\
\hline & & & & & \\
\hline \multirow[t]{10}{*}{$\mathbf{B}$} & & Biaya Proyek (Project - Related Cost) & & & \\
\hline & 1 & Biaya untuk mengumpulkan data & $\mathrm{Rp} \quad 1,200,000$ & & \\
\hline & & a. Biaya observasi di klinik & & & \\
\hline & 2 & Cetak undangan kerjasama dengan perusahaan & $\mathrm{Rp} \quad 8,400,000$ & & \\
\hline & & $(10 \times$ Rp. $70,000 \times 12)$ & & & \\
\hline & 3 & Biaya perlengkapan kantor: & & & \\
\hline & & a. Fotocopy dan laminating (dalam setahun) & Rp $\quad 4,980,000$ & & \\
\hline & & b. Kuitansi tanda rawat jalan dan inap & $\mathrm{Rp} \quad 5,400,000$ & & \\
\hline & & $(30 \times \mathrm{Rp} 15.000 \times 12)$ & & & \\
\hline & & c. Odner dan map $(5 \times$ Rp 18.000 x 12) & $\mathrm{Rp} \quad 1,080,000$ & & \\
\hline & & d. Pulpen $(2 \times 1$ dus $\times$ Rp $36.500 \times 12)$ & 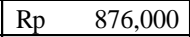 & & \\
\hline & & e. Kertas A4 1 rim 70gr (2 x Rp 30.000 x12) & \begin{tabular}{ll|}
$\mathrm{Rp}$ & 720,000 \\
\end{tabular} & & \\
\hline & & f. Kertas F4 1 rim 70gr ( 2 x Rp 35.000 x12) & $\begin{array}{ll}\mathrm{Rp} & 840,000 \\
\end{array}$ & & \\
\hline & & g. Tinta Printer (Epson 664, 1 set x 12) & Rp $4,800,000$ & & \\
\hline & & h. Materai $(10$ x Rp 7.000 x 12) & $\mathrm{Rp} \quad 840,000$ & & \\
\hline & & i. Buku folio (3 x Rp 20.000 x12) & $\mathrm{Rp} \quad 720,000$ & & \\
\hline & 4 & Biaya Depresiasi Perangkat Keras : & & & \\
\hline & & a. Perangkat Keras (Pc, Monitor, Keyboard, Printer & $\mathrm{Rp} \quad 1,609,200$ & & \\
\hline & & mouse,dsb) & & & \\
\hline & 5 & Biaya listrik/air/telephone/internet & & & \\
\hline & & a. Biaya listrik (setahun) & $\mathrm{Rp} 29,400,000$ & & \\
\hline & & b. Telephone (setahun) & $\mathrm{Rp} \quad 4,500,000$ & & \\
\hline & & c. PAM (setahun) & $\mathrm{Rp} \quad 4,980,000$ & & \\
\hline & & d. Internet (Speedy) (setahun) & $\mathrm{Rp} \quad 2,010,000$ & & \\
\hline & 6 & Biaya lain - lain (Miscelleneous Expense) & & & \\
\hline & & a. Transport rapat kerjasama ke perusahaan & $\mathrm{Rp} \quad 1,800,000$ & & \\
\hline & & $(10 \times 12 \times \operatorname{Rp} 15.000)$ & & & \\
\hline & & b. Transport antar laporan dan bayar BPJS (Rp 20.000 x 12) & $\mathrm{Rp} \quad 240,000$ & & \\
\hline & & Total Biaya & Rp 74,395,200 & & \\
\hline \multirow[t]{4}{*}{$\mathbf{C}$} & & Biaya Perawatan & & & \\
\hline & & a. Tukang Service Komputer $(\mathrm{Rp} 100.000$ x 12) & $\mathrm{Rp} \quad 1,200,000$ & & \\
\hline & & b. Install Ulang Komputer (Rp 150.000 x 12) & $\mathrm{Rp} \quad 1,800,000$ & & \\
\hline & & Total Biaya & $\begin{array}{|ll|}R p & 3,000,000 \\
\end{array}$ & & \\
\hline \multicolumn{3}{|r|}{ TOTAL KESELURUHAN BIAYA } & \begin{tabular}{|l|} 
Rp 82,195,200 \\
\end{tabular} & & \\
\hline
\end{tabular}

Sumber: Data Diolah, (2016) 
Tabel 3.

Analisis Biaya Pengembangan Proyek Sistem Baru

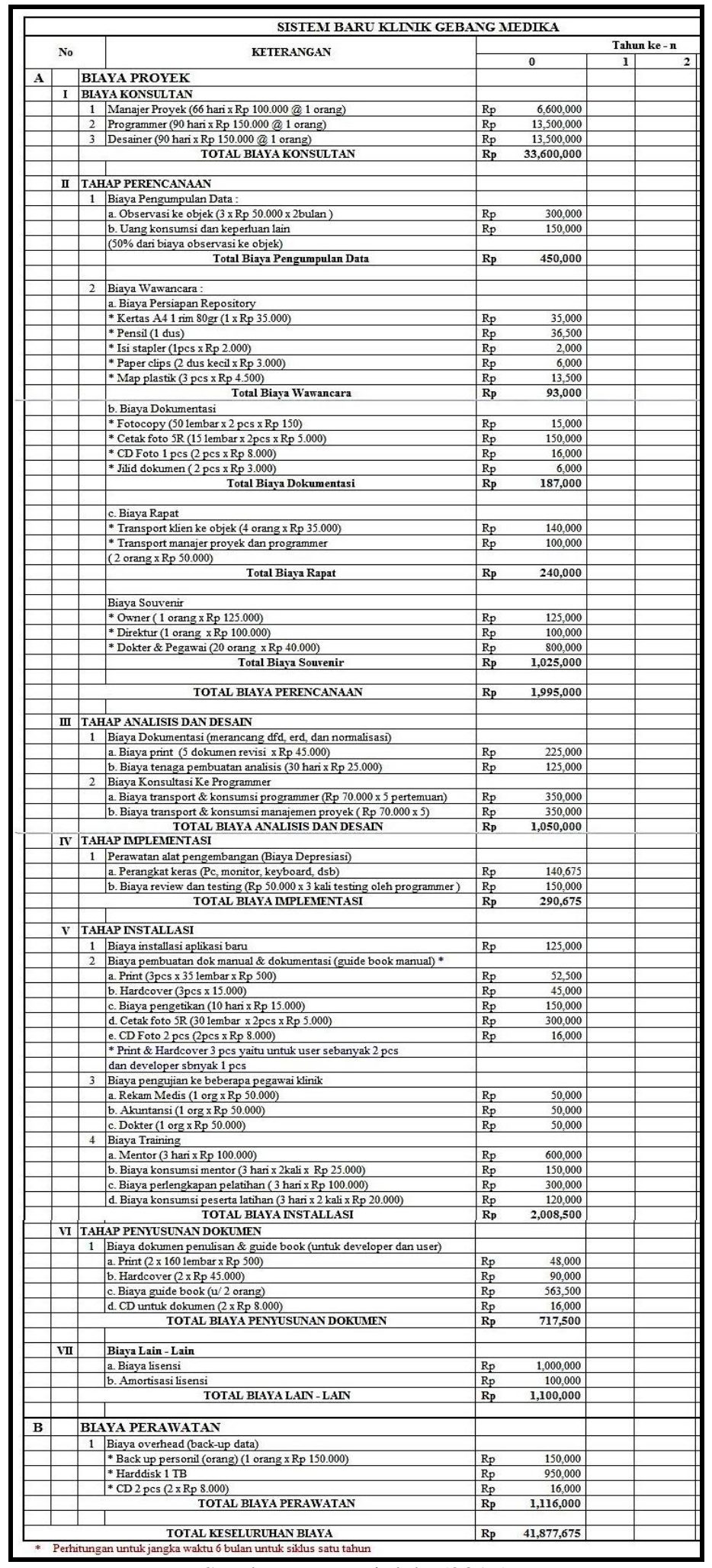

Sumber: Data Diolah, (2016) 


\section{Cara Menciptakan Added Value terhadap Sistem Informasi Akuntansi Pelayanan Pasien Rawat Jalan dan Rawat Inap pada Rumah Bersalin dan Klinik Gebang Medika}

Penambahan nilai (Added Value) pada sistem informasi akuntansi pelayanan rawat jalan dan rawat inap pada Rumah Bersalin dan Klinik Gebang Medika adalah sebagai berikut:

1. Dapat mengoptimalkan kualitas pelayanan

Hasil yang diberikan dari sebuah sistem yang baru adalah informasi berupa hasil pemeriksaan sangat akurat serta mudah di dapat. Informasi ini berupa softcopy yang dapat dicetak dan dapat digunakan untuk mengoptimalkan pelayanan terhadap pasien.

2. Meningkatkan efisiensi waktu pelayanan terhadap pasien dan pembuatan laporan

Pelayanan pasien pada saat mendaftar di sistem baru di harapkan dapat selesai dalam waktu kurang lebih 5 menit karena sudah menggunakan sistem database yang terstruktur dengan baik sedangkan pada sistem lama membutuhkan waktu sekitar 15 menit.

Pembuatan laporan dengan menggunakan sistem baru membutuhkan waktu sekitar dua jam berbeda dengan sistem yang lama yaitu membutuhkan waktu satu minggu untuk membuat sebuah laporan. Dari penjelasan tersebut terlihat bahwa waktu yang digunakan pada sistem baru lebih efisien daripada sistem lama.

3. Dapat meningkatkan struktur pengendalian internal

Pada sistem yang baru, sistem dirancang agar dapat diakses oleh semua bagian sesuai dengan tugas dan tanggung jawab masing-masing sehingga setiap bagian yang memiliki otorisasi bisa masuk ke dalam sistem. Penyimpanan dokumen pada sistem lama masih manual dan disimpan dalam bentuk arsip-arsip. Berbeda dengan sistem baru, di mana penyimpanan dokumen sudah menerapkan sistem database yang baik sehingga bila diperlukan dapat dicari dengan lebih mudah dan terstruktur dengan baik.

4. Meningkatkan pengambilan keputusan

Informasi yang dihasilkan dari sistem yang baru sangat mudah diakses dan akurat sehingga manajemen klinik dapat menggunakan informasi tersebut untuk pengambilan keputusan jangka panjang.

\section{E. SIMPULAN}

Proses dan prosedur pelayanan pasien rawat jalan dan rawat inap pada klinik ini dimulai dari pasien datang ke klinik kemudian melakukan pemeriksaan ke poliklinik yang dituju lalu diperiksa dan diberikan salinan resep oleh dokter. Kemudian akan diberikan juga kuitansi pembayaran dan pasien melakukan transaksi pembayaran pada kasir dan mendapatkan kuitansi serta salinan resep 
sebagai pengantar untuk mendapatkan sebuah obat. Proses pelayanan pasien ini melibatkan beberapa bagian yaitu direktur, kepala installasi rawat jalan, kepala installasi rawat inap, kepala installasi farmasi, installasi laboratorium, dokter, bidan, administrasi, rekam medis, perawat, kasir, akuntansi, keuangan, serta pendaftaran.

Biaya pengembangan proyek terdiri dari dua yaitu analisis sistem lama dan analisis sistem yang baru. Terdapat perbedaan jumlah biaya pengembangan proyek antara sistem lama dan sistem baru. Sistem lama membutuhkan biaya pengembangan proyek selama setahun sebesar Rp 82.195.200,- sedangkan sistem baru membutuhkan biaya pengembangan proyek selama setengah tahun (enam bulan) sebesar Rp 41.877.675,-.Jika di amati, biaya pengembangan sistem baru terlihat lebih besar bila di kalkulasikan selama setahun yaitu menjadi Rp 83.755.350,-. Hal ini disebabkan karena pada tahun pertama pengembangan proyek sistem baru terdapat sejumlah biaya yang harus dikeluarkan yakni biaya analisis dan desain, biaya installasi, biaya implementasi, dan biaya lain-lain yang besar nilainya.

Penambahan nilai (value-added) pada klinik ini adalah sebagai berikut, yaitu (1) dapat mengoptimalkan kualitas pelayanan, (2) meningkatkan efisiensi waktu pelayanan terhadap pasien dan pembuatan laporan, (3) dapat meningkatkan struktur pengendalian internal, (4) meningkatkan pengambilan keputusan. Mengoptimalkan kualitas pelayanan yang dimaksud adalah sebuah informasi berupa hasil pemeriksaan yang sangat akurat dan mudah diakses sehingga dapat digunakan untuk melayani pasien. Meningkatkan efisiensi waktu pelayanan dan pembuatan laporan yang dimaksud adalah ketika pasien mendaftar pada sistem baru dapat di selesaikan dalam waktu singkat karena menggunakan sistem database dan pembuatan laporan hanya membutuhkan waktu sekitar dua jam. Meningkatkan struktur pengendalian internal yaitu sistem baru dirancang agar dapat diakses oleh bagian yang sesuai dengan tugas dan tanggung jawabnya sehingga setiap bagian yang memiliki otorisasi bisa mengakses sistem tersebut. Meningkatkan pengambilan keputusan ialah manajemen klinik dapat menggunakan informasi yang akurat yang dihasilkan oleh sistem baru untuk pengambilan keputusan jangka panjang. 


\section{DAFTAR PUSTAKA}

Bodnar, G. H., \& Hopwood, W. S. (2007). Sistem Informasi Akuntansi (9 ed.). Yogyakarta, Jawa tengah, Indonesia: Andi.

Romney, M. B., \& Steinbart, P. J. (2014). Sistem Informasi Akuntansi (1 ed.). Jakarta, DKI Jakarta, Indonesia: Salemba Empat.

S, F. N., Prasetijo, Budi, A., \& Handoyo, E. (2011). Implementasi Sistem Informasi Rumah Sakit utuk Subsistem Farmasi. Universitas Diponegoro, Teknik Elektro. Semarang: Universitas Diponegoro.

Tebiary, A. A., Suastika, I. K., \& Ma'ruf, B. (2017). Analisis Non Value Added Activity Pada Proses Produksi Kapal Dengan Pendekatan Value Stream Mapping: Studi Kasus di PT. Dumas Tanjung Perak Shipyard Surabaya. Jurnal WAFE, 11 (1), 23-30.

Kementerian Kesehatan. 2013. Badan Penyelenggara Jaminan Kesehatan.

Peraturan Menteri Kesehatan Nomor 138 Tahun 2009 tentang Rawat Inap.

Peraturan Menteri Kesehatan Nomor 28 Tahun 2011 tentang Klinik.

Peraturan Menteri Kesehatan Nomor 560 Tahun 2003 tentang Tarif Rumah Sakit.

Undang-undang Nomor 29 Tahun 2004 tentang Praktek Kedokteran. 